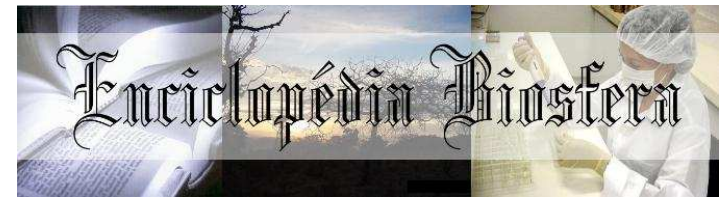

\title{
OBTENÇÃO E CARACTERIZAÇÃO DA FARINHA A PARTIR DE SILAGEM ÁCIDA DO RESÍDUO DA FILETAGEM DO TAMBAQUI CULTIVADO
}

\author{
Illana de Araujo Ribeiro ${ }^{1}$, Suezilde da Conceição Amaral Ribeiro², Jeferson Stiver \\ Oliveira de Castro $^{3}$, Gleicy Kelly China Quemel Medeiros ${ }^{4}$ \\ ${ }^{1}$ Graduada em Engenharia de Pesca, Universidade Federal Rural da Amazônia \\ (jestolca32@gmail.com) Belém - Brasil \\ ${ }^{2}$ Professora e Pesquisadora do Programa de Mestrado em Ciências Ambientais da \\ Universidade do Estado do Pará \\ ${ }^{3}$ Mestrando do Programa de Pós-Graduação em Ciências Ambientais, Universidade \\ do Estado do Pará \\ ${ }^{4}$ Mestre em Ciência Ambientais, Universidade do Estado do Pará
}

Recebido em: 08/09/2015 - Aprovado em: 14/11/2015 - Publicado em: 01/12/2015 DOI: http://dx.doi.org/10.18677/Enciclopedia_Biosfera_2015_201

Devido à escassez e o elevado preço de fontes proteicas, o aproveitamento dos resíduos para a geração de subprodutos industriais tem gerado grande interesse. A silagem ácida de resíduo de pescado apresenta-se como alternativa na obtenção de material rico em proteína a ser utilizado na elaboração de ração animal. O presente trabalho visou obter e caracterizar a silagem ácida de resíduos de filetagem do tambaqui em quatro momentos de estocagem diferentes e determinar a composição proximal da farinha desengordurada. Utilizou-se ácido acético glacial como agente acidificante em duas porcentagens distintas, $10 \%(\mathrm{C} 1)$ e 13,5\%(C2). Analisaram-se a composição química das silagens quanto a umidade, proteínas, lipídios e cinzas nos quatro momentos de estocagem diferentes: após a adição do ácido acético (T0), no sétimo dia (T7), no décimo quinto dia (T15) e no vigésimo dia de estocagem (T20). Avaliaram-se estatisticamente as médias dos resultados através do Teste de Tukey $(p>0,05)$. As temperaturas durante o tempo de estocagem variaram de $20,9^{\circ} \mathrm{C}$ a $3^{\circ} \mathrm{C}$. O pH variou 3,6 a 4,3. Para os parâmetros umi dade, cinzas e lipídios não foram verificadas diferenças estatísticas significativas. Foram obtidos para as

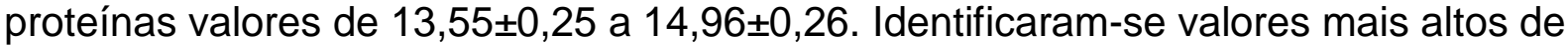
proteínas no décimo quinto dia de estocagem de silagem para os dois tratamentos (C1 e C2). As farinhas desengorduradas de silagens apresentaram boa qualidade nutricional quanto aos teores de proteínas e minerais. A composição proximal se encontra de acordo com a legislação vigente.

PALAVRAS- CHAVE: Composição Proximal, Pescado, Subproduto 


\title{
OBTAINING AND CHARACTERIZATION OF FLOUR THE SILAGE ACID FROM THE WASTE OF THE GROWN TAMBAQUI FILLETING
}

\begin{abstract}
Due to the shortage and high price of protein sources, the recovery of waste for the generation of industrial by-products has generated great interest. The acid silage of fish waste is presented as an alternative in getting material rich in protein to be used in the preparation of animal feed. This present work aims to obtain and characterize the acid silage filleting the tambaqui waste at four times in different storage and determine the proximate composition defatted flour. In this process was used glacial acetic acid as acidifying agent in two different percentages, $10 \%$ (C1) and $13.5 \%$ (C2).They were analyzed chemical composition of silages for moisture, protein, fat and ash in the four times of different storage: after addition of acetic acid (T0), on the seventh (T7) on the fifteenth day (T15) and twentieth day of storage (T20). They were evaluated statistically the average of the results through the Tukey test $(p>$ 0.05). The temperatures during the storage time varied from $20.9^{\circ} \mathrm{C}$ to $30^{\circ} \mathrm{C}$. The $\mathrm{pH}$ ranged 3.6 4.3. For the humidity parameters, ash and lipid and statistically significant differences were not verified. Proteins were obtained for values of $13.55 \pm$ $0.2514 .96 \pm 0.26$ the. Higher amounts of protein were identified on the fifteenth day silage storage for both treatments ( $\mathrm{C} 1$ and $\mathrm{C} 2)$. The defatted flours silages showed good nutritional quality and the levels of protein and minerals. The proximal composition is in line with current legislation.
\end{abstract}

KEYWORDS : Proximal Composition, Fish, Byproducts.

\section{INTRODUÇÃO}

A produção mundial de cultivo de espécies de peixe para o consumo humano em 2010 ficou em 59,9 milhões de tonelada, representando um aumento de 7,5\% em relação às 55,7 milhões de toneladas em 2009. A taxa de produção das espécies cultivadas no período compreendido entre 1980 e 2010 foi superior a da população mundial $(1,5 \%)$ e o consumo médio anual per capita de espécies cultivadas aumentou sete vezes. A partir dos anos 90 a aquicultura tem sido o motor de crescimento da produção pesqueira total desde que a produção mundial se estabilizou (FAO, 2014).

A produção aquícola brasileira atingiu em 2011 o volume de 628 mil toneladas e a pesca extrativa 800 mil toneladas, o que representa um volume total de 1,4 milhão de toneladas de pescados por ano, segundo o Ministério da Pesca e da Aquicultura (MPA). A piscicultura continental é responsável por quase $87 \%$ desse crescimento, com destaque para o tambaqui e a tilápia (SEBRAE, 2014). Em relação à importância econômica das regiões, o nordeste se destaca como maior produtora com $29 \%$ da produção nacional, seguido pelo sul e centro-oeste, respectivamente, $23 \%$ e $22 \%$, norte com $15 \%$ e sudeste com $11 \%$ (SEBRAE, 2015).

Segundo SEBRAE (2011), a tendência de crescimento da produção de pescado no Brasil, confirmada pelo maior volume não somente das partes comestíveis destes animais à disposição dos consumidores, mas também pelo aumento dos resíduos, cria a necessidade de uma destinação, no mínimo, ambientalmente correta para as partes não aproveitadas para consumo humano.

Uma das alternativas para esse aproveitamento de resíduos é a silagem do pescado. Esse processo é uma técnica antiga, que foi adaptada dos métodos de preservação de forrageiras com ácido sulfúrico e clorídrico, muito difundida nos 
países nórdicos. A silagem ácida de pescado é um produto liquefeito resultante de um peixe inteiro, ou que esteja impróprio para consumo, ou de resíduos de beneficiamento (cabeça, vísceras, escamas, nadadeiras e etc) que se preserva pela redução do pH por meio da adição de ácidos orgânicos e/ou inorgânicos (HISANO \& BORGHESI, 2011).

Este produto pode ser incorporado em rações como fonte de proteína, sendo de grande importância na utilização para formulação de rações destinadas aos animais domésticos, e viáveis em dietas extrusadas ou peletizadas de animais aquáticos (VIDOTTI, 2011; OLIVEIRA et al., 2013). Uma das espécies que se enquadra nesse aumento produtivo é o tambaqui, espécie nativa mais cultivada no Brasil. Segundo IZEL et al. (2013) o tambaqui é cultivado em todos os Estados da União com exceção de Santa Catarina e Rio Grande do sul, por necessidade de águas quentes. Tornou-se popular entre os consumidores devido ao sabor atrativo, pois além da disponibilidade nos supermercados brasileiros tem sido exportado à países europeus, como Portugal e França. O alto valor comercial do tambaqui devese a alta produtividade, bom potencial de crescimento, facilidade de adaptação a rações e a cativeiro, e o alto valor nutritivo (SANTOS et al., 2010; BORGES, 2013).

Dessa forma, o objetivo do trabalho foi avaliar a composição físico-química das farinhas produzidas por silagem ácida de resíduos oriundos da filetagem do tambaqui em quatro momentos de estocagem distintos e da farinha desengordurada produzida, considerando dois tratamentos com ácido acético glacial em diferentes concentrações, $10 \%$ (C1) e 13,5\% (C2).

\section{MATERIAL E MÉTODOS}

A matéria-prima utilizada para a obtenção da silagem ácida se constitui de resíduos (cabeça, vísceras, espinhas, nadadeira e restos de carne) oriundos da filetagem do Tambaqui. Os resíduos foram doados pela comunidade Cacoal, localizada no município de Santa Izabel. O município de Santa Izabel do Pará pertence a região metropolitana de Belém. A sede municipal tem as seguintes

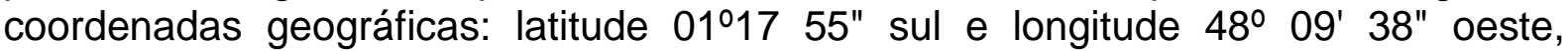
estando a uma altitude de 24 metros (ARAUJO, 2010)

Os resíduos foram coletados em Outubro de 2014, sendo imediatamente acondicionados em freezer a temperatura de $-18^{\circ} \mathrm{C}$. Para início da silagem 0 material foi descongelado por 48h. Em seguida a matéria-prima foi cortada em pedaços menores. Posteriormente, realizou-se a moagem dos mesmos em moedor industrial até a obtenção de uma massa homogênea. Em todos os ensaios foram utilizados $0,1 \%$ de Sorbato de Potássio como antifúngico e $0,1 \%$ de ácido cítrico com ação antioxidante (FAGBENRO \& JAUNCEY, 1995; VASCONCELOS et al., 2011; RIBEIRO et al., 2015).

Utilizou-se ácido acético como agente acidificante, em duas diferentes concentrações, $10 \%$ (C1) e 13,5\% (C2). A finalidade era de verificar a estabilidade físico-química das silagens durante o período de estocagem. As amostras da silagem foram colocadas em recipientes plásticos, sendo mantida a temperatura ambiente com revolvimento periódico durante os 20 dias de estocagem, a fim de garantir a qualidade da silagem e facilitar alguns processos bioquímicos até a estabilidade do $\mathrm{pH}$, aferido diariamente juntamente com a temperatura.

As análises das silagens foram executadas considerando quatro momentos de estocagem distintos: após a adição do ácido acético (T0), no sétimo dia de estocagem (T7), no décimo quinto dia (T15) e por fim no vigésimo dia (T20). 
A determinação da umidade dos resíduos de filetagem de tambaqui foi determinada pelo método de perda de massa por secagem. Foi realizada com a amostra in natura após a moagem nas silagens e nas farinhas. Após secagem em cadinhos de porcelana foram previamente aquecidas em estufa a $105^{\circ} \mathrm{C}$ por uma hora, resfriadas em dessecador até temperatura ambiente e as massas foram mensuradas em balança. Aproximadamente $5 \mathrm{~g}$ de amostras foram colocados nos cadinhos de porcelana, levadas em estufa a $10{ }^{\circ} \mathrm{C}$ p or três horas, resfriadas em dessecador e pesadas. Após este procedimento o controle por gravimetria foi realizado de uma em uma hora até massa constante.

A determinação das cinzas foi obtida em forno mufla a $550{ }^{\circ} \mathrm{C}$, durante seis horas. Inicialmente as amostras foram carbonizadas em $200 \stackrel{\circ}{ } \mathrm{C}$ e incineradas a 550 드, até que o material apresentasse cor branca ou cinza claro. Levados em dessecador para resfriar e pesadas em seguida.

A análise do teor de proteína foi realizada através da determinação do teor de nitrogênio pelo processo microKjeldahl, constituído de três etapas: digestão, destilação e titulação das amostras e utilizou-se o fator 6,25 para a conversão do total de nitrogênio para proteína .Mediu-se por gravimetria $0,2 \mathrm{~g}$ de amostra em papel em tubos de microkjedahl, e adicionou-se cinco $\mathrm{mL}$ de ácido sulfúrico concentrado e $1,0 \mathrm{~g}$ de mistura catalítica. Os tubos foram levados até o bloco digestor, onde ficaram sob aquecimento $\left(150-450^{\circ} \mathrm{C}\right)$ por aproximadamente quatro horas. Após atingirem temperatura ambiente, diluiu-se com água destilada (aproximadamente $10 \mathrm{~mL}$ ) Os tubos foram acoplado, um a um, para iniciar as análises em aparelho de destilação de nitrogênio. Acoplado ao equipamento, adicionou-se aproximadamente $25 \mathrm{~mL}$ de $\mathrm{NaOH} 50 \%$. Ligou-se o aquecimento. Foi preparada uma solução de ácido bórico $(2 \%)$ e $25 \mathrm{~mL}$ dessa solução foi adicionada a um erlenmeyer com cinco gotas de indicador de proteína. O erlenmeyer contendo o ácido bórico foi acoplado ao equipamento até completar o volume de $100 \mathrm{~mL}$. A solução foi titulada com ácido clorídrico $0,1 \mathrm{~N}$ até a viragem.

A determinação de lipídeos foi feita através da extração pelo método Soxhlet utilizando o éter de petróleo como solvente. Pesou-se cerca de $2 \mathrm{~g}$ de amostra em papel de filtro e colocou-se em cartucho de celulose. Montou-se o sistema de extração e adicionou-se $100 \mathrm{~mL}$ de éter de petróleo. Neste processo o solvente é aquecido e condensado passando pela amostra intermitentemente por seis horas.

Outro parâmetro físico-químico analisado foi o pH cujas determinações foram realizadas a cada $24 \mathrm{~h}$ durante sete dias e em 15 dias e 20 dias. Foi realizada também a análise sensorial das silagens ácidas durante o período de estocagem observando o comportamento das silagens a partir da elaboração e adição de ácidos, quanto aos parâmetros de aparência, aspecto uniforme, coloração, e odor ácido característico.

Para aperfeiçoar o aproveitamento do resíduo de filetagem de tambaqui e tornar a silagem mais estável optou-se pela remoção da umidade através de estufa de circulação e extração lipídica para a obtenção da farinha desengordurada. Após 0 vigésimo dia as amostras da silagem foram secas em estufas de circulação de ar forçado à $70^{\circ} \mathrm{C}$ por $36 \mathrm{~h}$, obtendo-se uma porção sólid a que foi triturada utilizando graal e pistilo até a obtenção da farinha de silagem integral (FSI) (GUILHERME et al., 2007).

Para extração do óleo da silagem foi utilizado método de extração à frio ,BLIGH DYER (1959). A utilização deste método para extração do óleo de silagem neste trabalho foi realizada apenas para fins qualitativos (RIBEIRO et al., 2015). 
Realizou-se a análise da composição química da farinha depois da extração do óleo. As análises físico-químicas (umidade, cinzas, proteínas e lipídeos) das silagens e da farinha foram realizadas nos Laboratórios de Química e Tecnologia de Alimentos do Centro de Ciências Naturais e Tecnologia (CCNT) da Universidade do Estado do Pará, sendo realizadas conforme metodologias recomendadas por INSTITUTO ADOLFO LUTZ (1985).

Os dados obtidos foram submetidos à análise de variância (ANOVA) e ao teste de comparações das médias de Tukey, a nível de 5\% e 1\% de probabilidade. O propósito foi detectar possíveis diferenças entre os dados analisados. As análises estatísticas foram realizadas com o auxílio dos softwares EXCEL 2010 e BIOESTAT 5.3.

\section{RESULTADOS E DISCUSSÃO}

Durante o período de estocagem foi observado que a liquefação ocorreu entre os $3^{\circ}$ e $5^{\circ}$ dias, aumentando a liquefação da silagem e diminuindo a viscosidade gradualmente até o final do período experimental, adquirindo características líquidopastosa, odor ácido, e coloração marrom claro, assim como observado por OLIVEIRA et al. (2006) em estudo com silagens de resíduos de tilápias do nilo. Atribui-se a liquefação à continua hidrólise proteica pela ação das enzimas proteolíticas, resultante da diminuição do $\mathrm{pH}$, através do ácido acético. Ao final do período experimental (15 a 20 dias), o aspecto sensorial das silagens apresentou-se líquida, odor ácido e aroma de ranço e coloração marrom acinzentada.

$\mathrm{O} \mathrm{pH}$ e a temperatura das silagens (Tabela 1) não variaram bruscamente durante o período de estocagem nos tratamentos $\mathrm{C} 1$ e $\mathrm{C} 2$. No primeiro dia houve queda brusca do $\mathrm{pH}$ devido a adição do ácido, conforme verificado por ARRUDA (2004), com pH por volta de 3,8 com silagem de resíduo de tilápia. A partir do segundo dia o pH manteve-se relativamente constante. Dessa forma, foi observado que não houve variação entre a temperatura e pH em relação aos dois tratamentos.

Os resultados encontrados por PESSOA (2012) também demonstraram que o $\mathrm{pH}$ não diferiu em função do tempo para cada silagem $(P>0,05)$ de peixes inteiros de tilápia no tempo de estocagem de um (T1) a 28 dias (T28).

TABELA 1 - Acompanhamento de pH e Temperatura das Silagens ácidas de tambaqui durante o período experimental.

\begin{tabular}{|c|c|c|c|c|}
\hline \multirow[t]{2}{*}{$\begin{array}{l}\text { Período } \\
\text { Experimental }\end{array}$} & \multicolumn{2}{|l|}{${ }^{1} \mathrm{C} 1$} & \multicolumn{2}{|l|}{${ }^{2} \mathrm{C} 2$} \\
\hline & Temp & $\mathrm{pH}$ & Temp & $\mathrm{pH}$ \\
\hline 1ㅇdia & 29,1 & 3,7 & 29,4 & 3,6 \\
\hline $2^{2} \mathrm{dia}$ & 28 & 4,1 & 27 & 4,0 \\
\hline $3^{\circ}$ dia & 29,5 & 4,3 & 29,7 & 4,2 \\
\hline $4^{\circ}$ dia & 29,1 & 4,3 & 28,9 & 4,2 \\
\hline 5dia & 27 & 4,3 & 27 & 4,2 \\
\hline 6olia & 29,4 & 4,1 & 29,2 & 4,2 \\
\hline 7 dia & 29,1 & 4,1 & 29,7 & 4,2 \\
\hline 15 dia & 30 & 4,3 & 29,9 & 4,2 \\
\hline 20 dia & 28,9 & 4,3 & 28,9 & 4,2 \\
\hline
\end{tabular}


Todos os resultados de $\mathrm{pH}$ ficaram abaixo de 4,5, o que indica uma estabilidade microbiológica para patogênicos e garantia da qualidade das silagens durante o período experimental. Para CARVALHO et al., (2006) o pH ácido diminui ou impede o crescimento de bactérias indesejáveis que causam a decomposição anaeróbica de proteínas e a putrefação.

Em trabalho realizado por ESPÍNDOLA FILHO et al. (2000), a silagem de pescado foi misturada a $7 \%$ de Carbonato de Cálcio, verificou-se $\mathrm{pH}$ de 4,5 no primeiro dia e 4,8 no $15^{\circ}$ dia. Em segundo experimento a silagem foi associada a $5 \%$ de pó de ostra, identificou-se no primeiro dia $\mathrm{pH}$ de 5,5 e no $15^{\circ}$ dia $\mathrm{pH}$ de 5,75 .

A tabela 2 apresenta a composição físico-química das silagens ácidas de resíduos relacionando os valores obtidos com o tempo de estocagem, a concentração do ácido e a matéria-prima da silagem.

TABELA 2 - Composição físico-química das silagens de resíduos de Tambaqui em cada tempo de estocagem.

\begin{tabular}{|c|c|c|c|c|c|}
\hline \multirow{2}{*}{\multicolumn{2}{|c|}{$\begin{array}{l}\text { Tempo } \\
\text { (dias)/Tratamentos }\end{array}$}} & \multicolumn{4}{|c|}{ Composição Físico-química } \\
\hline & & Umidade \% & Cinzas \% & Proteínas \% & Lipídeos\% \\
\hline & $\begin{array}{l}\text { Matéria } \\
\text { Prima }\end{array}$ & $65,62 \pm 0,42^{c}$ & $5,18 \pm 0,29^{a}$ & $15,68 \pm 0,86^{a}$ & $11,90 \pm 1,36^{\mathrm{a}}$ \\
\hline${ }^{3} \mathrm{TO}$ & $\begin{array}{l}{ }^{1} 10 \% \\
{ }^{2} 13,5 \%\end{array}$ & $\begin{array}{l}68,93 \pm 0,26^{\mathrm{ab}} \\
68,44 \pm 0,31^{\mathrm{b}}\end{array}$ & $\begin{array}{l}3,76 \pm 0,16^{b} \\
3,86 \pm 0,35^{b}\end{array}$ & $\begin{array}{l}13,55 \pm 0,25^{b} \\
13,79 \pm 0,19^{b}\end{array}$ & $\begin{array}{l}11,62 \pm 0,05^{\mathrm{a}} \\
11,71 \pm 0,41^{\mathrm{a}}\end{array}$ \\
\hline${ }^{4} \mathrm{~T} 7$ & $\begin{array}{l}{ }^{1} 10 \% \\
{ }^{2} 13,5 \%\end{array}$ & $\begin{array}{l}68,80 \pm 0,72^{\underline{a}} \\
69,02 \pm 0,17^{\underline{a}}\end{array}$ & $\begin{array}{l}3,49 \pm 0,39^{a} \\
3,66 \pm 0,16^{a}\end{array}$ & $\begin{array}{l}13,79 \pm 0,05^{\underline{a}} \\
13,45 \pm 0,11^{\text {a }}\end{array}$ & $\begin{array}{l}11,62 \pm 0,40^{\mathrm{a}} \\
11,83 \pm 0,12^{\mathrm{a}}\end{array}$ \\
\hline${ }^{5} \mathrm{~T} 15$ & $\begin{array}{l}{ }^{1} 10 \% \\
213,5 \%\end{array}$ & $\begin{array}{l}69,04 \pm 0,41^{\text {a }} \\
68,77 \pm 0,41^{\text {a }}\end{array}$ & $\begin{array}{l}3,88 \pm 0,26^{a} \\
4,23 \pm 0,34^{a}\end{array}$ & $\begin{array}{l}14,87 \pm 0,56^{\underline{a}} \\
14,96 \pm 0,26^{\underline{a}}\end{array}$ & $\begin{array}{l}11,81 \pm 0,34^{\mathrm{a}} \\
11,30 \pm 0,15^{\mathrm{a}}\end{array}$ \\
\hline${ }^{6} \mathrm{~T} 20$ & $\begin{array}{l}{ }^{1} 10 \% \\
213,5 \%\end{array}$ & $\begin{array}{l}68,32 \pm 0,38^{\underline{a}} \\
68,43 \pm 0,29^{\underline{a}}\end{array}$ & $\begin{array}{l}3,21 \pm 0,11^{\mathrm{b}} \\
4,44 \pm 0,5^{\mathrm{a}}\end{array}$ & $\begin{array}{l}14,69 \pm 0,86^{\underline{a}} \\
14,20 \pm 0,47^{\text {a }}\end{array}$ & $\begin{array}{l}9,76 \pm 0,04^{b} \\
10,31 \pm 0,27^{a}\end{array}$ \\
\hline
\end{tabular}

$110 \%$ de ácido acético: $\mathrm{C} 1 ;{ }^{2} 13,5 \%$ de ácido acético: C2

${ }^{3}$ T0: Tempo 0; ${ }^{4}$ T7: Sétimo dia de estocagem; ${ }^{5} \mathrm{~T} 15$ : décimo quinto dia de estocagem; ${ }^{6} \mathrm{~T} 20$ : vigésimo dia de estocagem

Para cada tempo, letras distintas na mesma coluna indicam diferença estatística; significativo ao nível de $5 \%$ de probabilidade $(p<0.05)$.

Os teores de umidade, cinzas e proteínas não apresentaram diferenças em relação as diferentes concentrações de ácido acético C1e C2, Observaram-se diferenças estatísticas significativas entre os valores de umidade, cinza e proteína da matéria-prima in natura, sem a adição do ácido, e os teores encontrados nos dois tratamentos (C1 e C2) nos quatro momentos de estocagem distintos (T0, T5, T15 e T20). Identificaram-se maiores valores na composição química para os resíduos sem adição do acidificante. A possível explicação para essa diferença deve-se a diluição que o ácido proporcionou aos dois tratamentos. Apenas os valores de lipídios não diferiram significativamente da matéria-prima.

Não foi observado no sétimo dia (T7) de estocagem diferença significativa entre as médias dos valores da composição química da silagem nos tratamentos, demonstrando possivelmente 0 início da estabilidade físico-química. 0 comportamento de estabilidade físico-química continuou sendo observado no décimo quinto dia de estocagem (T15) tanto em C1 quanto em C2.

No vigésimo dia (T20) de estocagem não houve diferença significativa das médias entre os tratamentos no que diz respeito à umidade e proteínas. Já em 
relação às médias de cinzas e lipídeos foram verificadas diferenças entre C1 e C2. ARRUDA (2004) desenvolvendo silagem ácida de tilápia do Nilo, obteve valor de umidade de 78,32\%, superiores aos obtidos em T0, T7, T15 e T20. Os valores de cinzas de $4,17 \%$ encontrados pela autora foram próximos aos encontrados em T15. No entanto comparando-se os valores de proteínas de $12,85 \%$ e lipídeos de 3,89\% foram inferiores aos encontrados neste trabalho em todos os quatro momentos tempos de estocagem.

A tabela 3 demonstra os resultados da composição físico-química da silagem ácida em relação aos tratamentos C1 e C2 durante o período de estocagem

TABELA 3- Composição físico-química das silagens de resíduos de tambaqui por tratamento durante período de estocagem.

\begin{tabular}{|c|c|c|c|c|c|}
\hline \multirow{2}{*}{\multicolumn{2}{|c|}{$\begin{array}{l}\text { Tratamentos/ } \\
\text { Tempo(dias) }\end{array}$}} & \multicolumn{4}{|c|}{ Composição Físico-química } \\
\hline & & \multirow{2}{*}{$\begin{array}{l}\text { Umidade } \\
68,93 \pm 0,26^{\mathrm{a}}\end{array}$} & \multirow{2}{*}{$\begin{array}{l}\text { Cinzas } \\
3,76 \pm 0,16^{\mathrm{ab}}\end{array}$} & \multirow{2}{*}{$\begin{array}{l}\text { Proteínas } \\
13,55 \pm 0,25^{\mathrm{a}}\end{array}$} & \multirow{2}{*}{$\begin{array}{l}\text { Lipídeos } \\
11,62 \pm 0,05^{\mathrm{a}}\end{array}$} \\
\hline Ácido & ${ }^{3} \mathrm{TO}$ & & & & \\
\hline Acético & ${ }^{4} \mathrm{~T} 7$ & $68,80 \pm 0,72^{a}$ & $3,49 \pm 0,39^{a b}$ & $13,79 \pm 0,05^{a}$ & $11,62 \pm 0,40^{a}$ \\
\hline \multirow[t]{2}{*}{$10 \%$} & ${ }^{5} \mathrm{~T} 15$ & $69,04 \pm 0,41^{a}$ & $3,88 \pm 0,26^{a}$ & $14,87 \pm 0,56^{a}$ & $11,81 \pm 0,34^{a}$ \\
\hline & ${ }^{6} \mathrm{~T} 20$ & $68,32 \pm 0,38^{a}$ & $3,21 \pm 0,11^{b}$ & $14,69 \pm 0,86^{a}$ & $9,76 \pm 0,04^{b}$ \\
\hline Ácido & ${ }^{3} \mathrm{TO}$ & $68,44 \pm 0,31^{a}$ & $3,86 \pm 0,35^{a}$ & $13,79 \pm 0,19^{b}$ & $11,71 \pm 0,41^{a}$ \\
\hline Acético & ${ }^{4} \mathrm{~T} 7$ & $69,02 \pm 0,17^{a}$ & $3,66 \pm 0,16^{a}$ & $13,45 \pm 0,11^{b}$ & $11,89 \pm 0,12^{a}$ \\
\hline \multirow[t]{2}{*}{$13,5 \%$} & ${ }^{5} \mathrm{~T} 15$ & $68,77 \pm 0,41^{a}$ & $4,23 \pm 0,34^{a}$ & $14,96 \pm 0,26^{a}$ & $11,30 \pm 0,15^{a}$ \\
\hline & ${ }^{6} \mathrm{~T} 20$ & $68,43 \pm 0,29^{a}$ & $4,44 \pm 0,52^{a}$ & $14,20 \pm 0,47^{b}$ & $10,31 \pm 0,27^{b}$ \\
\hline
\end{tabular}

${ }^{3}$ T0: Tempo 0; ${ }^{4}$ T7: Sétimo dia de estocagem; ${ }^{5}$ T15: décimo quinto dia de estocagem; ${ }^{6}$ T20: vigésimo dia de estocagem

Para cada tratamento, letras distintas na mesma coluna indicam diferença estatística; significativo ao nível de $5 \%$ de probabilidade $(p<0.05)$.

Fonte: Autores

O comportamento das composições do tratamento com ácido acético a $10 \%$ durante os tempos de estocagem não apresentaram diferenças significativas entre as médias dos teores de umidade e proteínas. No entanto, houve uma diminuição de lipídeos do T20 em relação aos tempos anteriores. As médias dos teores de cinzas também não apresentaram diferenças significativas entre T0 e T7 com T15 e entre T0 e T7 com T20, porém T15 diferiu significativamente em relação a T20, não apresentando uma relação direta com o tempo de estocagem.

Sobre o comportamento das composições proximais da farinha produzida por silagem utilizando ácido acético à $13,5 \%$, observou-se que em todos os tempos de estocagem as médias de umidade e cinzas não apresentaram diferenças significativas. Durante sete dias não houve diferença significativa para as médias de proteínas, que a partir do $15^{\circ}$ dia teve um aumento, decaindo novamente em T20. Para lipídeos, as médias durante os tempos T0, T7 e T15 não apresentaram diferenças significativas, sendo verificada em T20 uma diminuição deste teor.

VASCONCELOS et al. (2011) utilizando ácido acético para obtenção de silagem ácida de resíduos de tilápias constatou valores de proteínas de 40,71\%, cinzas de 6,60\% e lipídeos de 26,49\%. Estes valores foram superiores aos encontrados neste trabalho em todos os tratamentos. Entretanto para umidade a porcentagem de $67,92 \%$ foi moderadamente inferior ao encontrado neste trabalho,

Nos resultados da análise de cinzas verificou-se um comportamento similar entre os tratamentos até o $15^{\circ}$ dia. Percebe-se após este período uma queda no teor 
de cinzas no $20^{\circ}$ dia para $\mathrm{C} 1(3,21 \pm 0,11)$, enquanto ocorre uma continua elevação deste mesmo teor em C2 $(4,44 \pm 0,52)$. Isto pode ter ocorrido devido a influência que maiores concentrações de ácido exercem na solubilização dos minerais presentes nas silagens. VIDOTTI \& GONÇALVES (2006) em silagem ácida (ácido fórmico + ácido sulfúrico) observaram valor de $5,09 \%$ de cinzas.

Nos lipídios o comportamento global das silagens foi semelhante para todos os tratamentos, observando uma ligeira queda no $20^{\circ}$ dia. A diminuição dos lipídeos também foi evidenciada por OLIVEIRA et al., (2013) em silagens de resíduos de tilápias do Nilo. Para as proteínas observou-se alta biodisponibilidade em T15 nos dois tratamentos, provocada pela ação das proteases endógenas presentes no tecido do pescado, o que produz aumento de solubilização das proteínas. Uma relação identificada no experimento foi a alta concentração de proteínas no décimo quinto dia e a alta temperatura, que pode ter otimizado e ativado as enzimas, influenciando no valor final.

Os resultados das análises físico-químicas das farinhas da silagem ácida dos resíduos de tambaqui estão apresentados na tabela 4

TABELA 4 - Composição proximal das farinhas Desengorduradas das silagens de resíduos de tambaqui.

\begin{tabular}{lllll}
\hline Farinha & Umidade & Cinzas & Proteínas & Lipídeos \\
\hline${ }^{7} \mathrm{~F} 1$ & $4,81 \pm 0,14^{\mathrm{c}}$ & $21,03 \pm 0,92^{\mathrm{b}}$ & $66,16 \pm 0,69^{\mathrm{a}}$ & $0,34 \pm 0,06^{\mathrm{a}}$ \\
${ }^{8} \mathrm{~F} 2$ & $5,94 \pm 0,28^{\mathrm{b}}$ & $23,59 \pm 0,36^{\mathrm{a}}$ & $61,72 \pm 3,54^{\mathrm{a}}$ & $0,54 \pm 0,37^{\mathrm{a}}$ \\
\hline
\end{tabular}

${ }^{7} \mathrm{~F} 1:\left(10 \%\right.$ de ácido acético); ${ }^{8} \mathrm{~F} 2:(13,5 \%$ de ácido acético)

Letras distintas na mesma coluna indicam diferença estatística; significativo ao nível de $1 \%$ de probabilidade $(p<0.01)$

As farinhas apresentaram umidade diretamente proporcional à adição de ácido acético. O ácido proporciona uma diluição na silagem e consequentemente afeta na composição das farinhas. Valores de cinzas encontrados nas farinhas foram próximos aos valores encontrado por BENITES (2003) em farinhas de silagem de 15 e 30 dias de estocagem, que foram de $20,65 \%$ e $21,20 \%$ respectivamente, e inferiores aos encontrados por VASCONCELOS et al., (2011) para farinhas de silagens secas e parcialmente desengorduradas com valores de cinzas de $36,82 \%$.

O maior teor de cinzas foi observado em F2 de 23,59\%. No entanto, este valor foi inferior ao encontrado por BOELTER et al. (2011) que encontraram 27,20\% de cinzas com farinha de silagem de sardinha. Ácidos orgânicos como o ácido acético, solubilizam a matéria orgânica, deixando em solução os minerais, resultando em alta concentração destes minerais na matéria seca.

O teor de lipídeos após extração não apresentou diferença significativa, demonstrando a eficiência da extração. O mesmo método foi utilizado por ARRUDA (2004) em extração de óleo bruto de resíduo de Tilápia do Nilo. De acordo com o artigo 471 do Regulamento da Inspeção Industrial e Sanitária de produtos de Origem Animal - RIISPOA (BRASIL, 1980) as farinhas desengorduradas F1 e F2 foram classificadas de primeira qualidade com teores de proteínas de 66,16 \% e 61,72\%.

\section{CONCLUSÃO}

A silagem ácida elaborada a partir dos resíduos de filetagem do Tambaqui atingiu a estabilidade total em todos os parâmetros proximais e em todos os tratamentos (C1 e C2) no T15 (décimo quinto dia). 
Para a obtenção da farinha desengordurada a silagem utilizada foi no máximo 20 dias de estocagem. As farinhas desengorduradas (F1 e F2) obtidas a partir da silagem ácida do Tambaqui foram consideradas de primeira qualidade, sendo consideradas ótimas fontes proteicas e lipídicas. Portanto, podem ser utilizadas como ingrediente alternativo na elaboração de ração animal.

\section{REFERÊNCIAS}

ARAUJO, A.R.M. de.; FLAVIO, R.; OBASHI, R. S.; MOURA, R. de L.; NASCIMENTO, J. N. de. Atividade de vivência em comunidade rural e sua importância para a formação extencionista do acadêmico de Agronomia - São Francisco do Itá - PA. In: CONGRESSO PAULISTA DE EXTENÇÃO UNIVERSITARIA, 2010. p.429.

ARRUDA, L. F. Aproveitamento do resíduo do beneficiamento da tilápias do nilo(Oreochromis niloticus) para obtenção de silagem e óleo como subprodutos. 2004. 78f. Dissertação (Mestrado em Ciências e Tecnologia de Alimentos) - Escola Superior de Agricultura "Luiz de Queiroz", Universidade de São Paulo. Piracicaba, 2004.

BENITES, C. I. Farinha de silagem de resíduo de pescado: elaboração,complementação com farelo de arroz e avaliação biológica em diferentes espécies. 2003. 159f. Dissertação (Mestrado em Engenharia de Alimentos). Universidade Federal do Rio Grande do Sul . Rio Grande, 2003.

BRASIL - Ministério da Agricultura. R.I.I.S.P.O.A. Regulamento da Inspeção Industrial e Sanitária de Produtos de Origem Animal (Aprovado pelo decreto $n^{0} 30690$, de 20.03.52, alterado pelo decreto $n^{0} 1255$, de 25.06.52). Brasília. 1980. $66 \mathrm{p}$.

BLIGH, E. D.;DYER, W. J. A Rapid Method of Total Lipid extraction and purification. Canadian Journal Biochemistry Physiology.v.37. p. 911-917,1959

BOELTER, J. F.; PEREIRA, A. C. da S. C.; PRADO, J. P. de S.; SOBRINHO, D. C.; MOTTA, A. L. de V.; CAVALHEIRO, J. M. O.Caracterização química e perfil de Aminoácido da Farinha de Silagem de resíduo de Sardinha. Revista Biologia e Farmácia.v.5,n., p.86-92, 2011

BORGES, A. Parâmetros de qualidade do Pacu (Piractus mesopotamicus), Tambaqui (Colossoma macropomum) e do seu híbrido eviscerados e estocados em gelo. 2013. 221f. Tese (Doutorado em Higiene Veterinária e Processamento Tecnológico de Produtos de Origem Animal) - Universidade Federal Fluminense. Niteroi, 2013

CARVALHO, G. G. P.; PIRES, A.J.V; VELOSO, C.M.; SILVA, F.F.; CARVALHO, B.M.A. Silagem de resíduo de peixes em dietas para alevinos de tilápia do Nilo. Revista Brasileira de Zootecnia, v.35, n.1, p.126-130, 2006. 
ESPÍNDOLA-FILHO, A.; OETTERER, M.; TRANI, P.E. Processamento agroindustrial de resíduos de peixes, camarões, mexilhões e ostras pelo sistema cooperativo, em setor de pescado. In: Work Shop - Tecnologia de Pescado. Ital. 2000

FAGBENRO, O. JAUNCEY, K. Growth and protein utilization by juvenileCatfish(clariasgariepinus) fed dry diets Containing co-dried lactic-acidfermented fishsilage and protein feedstuffs. Bioresource Technology 51 .p.29-35. Elsevier Science Limited Printed in Great Britain, 1995.

FAO - FOOD AND AGRICULTURE ORGANIZATION OF THE UNITED NATIONS. 2014. The State of World Fisheries and Aquaculture. FAO Fisheries and Aquaculture Department, Rome. Disponível em: http://www.fao.org/docrep/016/i2727e/i2727e00.htm . Acessado em 20 de Dezembro de 2014.

GUILHERME, R. F.; CAVALHEIRO, J. M. O.; SOUZA,P. A. S. Caracterização Química e Perfil Aminoácidico da Farinha de Silagem da Cabeça do Camarão. Revista Ciência e Agrotecnologia de Lavras. V.31,n 3, p. 793-797, 2007

HISANO, H.; BORGHESI, R. Elaboração de silagem ácida de vísceras de surubim ( Pseudoplatystoma sp.). Dourados: Embrapa Pecuária Oeste, 2011. 4 p. (Embrapa Pecuária Oeste. Circular Técnica, 18).

INSTITUTO ADOLFO LUTZ Normas Analíticas do Instituto AdolfoLutz. v. 1 Métodos Químicos e Físicos para Análise de Alimentos, 3. ed. Sao Paulo: IMESP, 1985

IZEL, A.C.U. et al. Boletim estatístico da pesca e aquicultura 2011. Ministério da pesca e aquicultura. Manaus: Embrapa Amazônia Ocidental, 2013, 4f. (Embrapa Amazônia Ocidental: Circular Técnica,39)

OLIVEIRA, M.M. de; PIMENTA, M. E. de S. G.; CAMARGO, A. C.; FIORINO, J. E.; PIMENTA, C. J. Silagem de resíduos da filetagem de Tilápia do Nilo (Oreochromisniloticus), com ácido fórmico- Análise Bromatológica, físico-química e microbiológica. Revista Cienc.Agrotec., Lavras, v.30, p.1218-1223, 2006.

OLIVEIRA, A. L. T. de.; SALES, R. de O.; FREITAS, J. B. S.; LOPES, J. E. L.Alternativa sustentável para descarte de resíduos de pescado em Fortaleza. Revista Brasileira de Higiene e Sanidade Animal, v. 7, n1, p. 1-8, 2013

PESSOA, M. S. Características físico-químicas e microbiológicas da silagem ácida de pescado.2012. 48f. Dissertação (Mestrado em Ciências Agrárias) Universidade Federal de Minas Gerais. Monte Carlos, 2012

SANTOS, L.; FILHO, M. P.; SOBREIRA, C.; ITUASSÚ, D.; FONSECA, F. A. L. da. Exigência protéica de juvenis de tambaqui (Colossomamacropomum) após privação alimentar. Acta Amazônica, v.40, p.597-604, 2010 
RIBEIRO, I. A.; RIBEIRO, S. da C. A.; CASTRO, J. S. O. de; MEDEIROS, G. K. C. Q.; SILVA, A. C. da.Aproveitamento do Óleo Bruto Obtido por Silagem Ácida de Resíduo de Pescado. Enciclopédia Biosfera. Goiânia, v11, n21, p203-211, 2015.

SEBRAE. Viabilidade Econômica e Financeira do Reaproveitamento do Resíduo do Pescado no Espírito Santo. Espírito Santo: SEBRAE, 2011. Disponível em: http://201.2.114.147/bds/bds.nsf/F9607813844ADE51832578BF005FDE21/\$File/Pro jeto\%20Utiliza\%C3\%A7\%C3\%A30\%20res\%C3\%ADduo\%20pescado\%20E.S\%2020 11.pdf. Acessado em : 29/ 07/ 2015.

SEBRAE. 1ํ Anuário brasileiro da pesca e aquicultura. Itajai: SEBRAE, 2014, . Disponível em :http://formsus.datasus.gov.br/novoimgarq/16061/2489520 218117.pdf . Acessado em 26/10/2015.

SEBRAE. Aquicutura no Brasil: série de estudos Mercadológicos. Brasília: SEBRAE, 2015.

Disponível em :http://www.bibliotecas.sebrae.com.br/chronus/ARQUIVOS CHRONUS/bds/bds.nsf/ 4b14e85d5844cc99cb32040a4980779f/\$File/5403.pdf. Acessado em 26/ 10/ 2015

VASCONCELOS, M. M. M.; MESQUITA, M. S. C.; ALBUQUERQUE, S. P. Padrões físicos-químicos e rendimento de silagem ácida de tilápia. Rev. Bras. Eng. Pesca. 6:p. 27-37. 2011.

VIDOTTI, R. M.; GONÇALVES, G. S. Produção e caracterização de silagem, farinha e óleo de tilápia e sua utilização na alimentação animal. Centro Avançado de Pesquisa Tecnológica do Agronegócio do Pescado Continental Instituto de Pesca-APTA-SAA. São José do Rio Preto, SP, Brasil, 2006.

VIDOTTI, R. M. Silagem de Pescado. In: GONÇALVES, A. A. Tecnologia do Pescado: Ciência, Tecnologia, Inovação e Legislação. Ed. Atheneu. São Paulo. 2011. 